OPEN ACCESS

Edited by:

Francesco Giuseppe Carbone,

Azienda Provinciale per i Servizi

Sanitari (APSS), Italy

Reviewed by:

Alessandro Rizzo,

Sant'Orsola-Malpighi Polyclinic, Italy

Giovanni Brandi,

University of Bologna, Italy

*Correspondence:

Jin-He Guo

jinheguo@sina.com

${ }^{\dagger}$ These authors have contributed equally to this work and share first authorship

Specialty section:

This article was submitted to Gastrointestinal Cancers,

a section of the journal

Frontiers in Oncology

Received: 23 February 2021 Accepted: 09 June 2021

Published: 29 June 2021

Citation:

Li H, Chen L, Zhu G-Y, Yao X,

Dong $R$ and Guo J-H (2021)

Interventional Treatment for

Cholangiocarcinoma

Front. Oncol. 11:671327.

doi: 10.3389/fonc.2021.671327

\section{Interventional Treatment for Cholangiocarcinoma}

\author{
Hang $\mathrm{Li}^{+}$, Li Chen ${ }^{\dagger}$, Guang-Yu Zhu ${ }^{\dagger}$, Xijuan Yao, Rui Dong and Jin-He Guo* \\ Center of Interventional Radiology and Vascular Surgery, Department of Radiology, Zhongda Hospital, Medical School, \\ Southeast University, Nanjing, China
}

Cholangiocarcinoma (CCA) is the second most common type of primary liver malignancy. The latest classification includes intrahepatic cholangiocarcinoma and extrahepatic cholangiocarcinoma, with the latter one further categorized into perihilar and distal cholangiocarcinoma. Although surgical resection is the preferred treatment for CCA, less than half of the patients are actually eligible for radical surgical resection. Interventional treatment, such as intra-arterial therapies, ablation, and brachytherapy (iodine-125 seed implantation), has become an acceptable palliative treatment for patients with unresectable CCA. For these patients, interventional treatment is helpful for locoregional control, symptom relief, and improving quality of life. Herein, in a timely and topical manner, we will review these advances and highlight future directions of research in this article.

Keywords: cholangiocarcinoma, interventional, intra-arterial therapies, ablation, brachytherapy

\section{INTRODUCTION}

Cholangiocarcinoma (CCA) originates from the epithelial cells of the biliary tree. As the second most common type of primary liver malignancy globally, it accounts for approximately $3 \%$ of gastrointestinal tumors and $10-25 \%$ of hepatobiliary malignancies (1). The global mortality and incidence of CAA are currently trending upwards (2). Various guidelines have been modified to guide treatment strategies as well as to predict prognosis for patients with CCA (3). The latest classification is made based on the anatomic location and includes intrahepatic cholangiocarcinoma (iCCA) and extrahepatic cholangiocarcinoma (eCCA), with the latter further categorized into perihilar (pCCA) and distal cholangiocarcinoma (dCCA) $(2,4,5)$. CCA is a group of heterogeneous diseases with different anatomy, epidemiology, etiology, pathogenesis, clinical presentations, and treatment modalities (4). The incidence of CCA varies by region, with more than $80 \%$ cases found in Asia and South America (6). Due to its aggressiveness, CCA is characterized by a high mortality rate and poor prognosis (1). Most patients with CCA present with several segments or vascular invasion and even local/distant metastasis. The 5-year survival of patients with CCA ranges from 20 to $35 \%(4,7,8)$. Currently, gemcitabine plus cisplatin (GC) is a standard chemotherapy regimen for unresectable CCA. Nevertheless, the prognosis is poor, with the median overall survival (OS) less than 1 year (9).

Immunotherapy has radically changed therapeutic algorithms of several hematologic and solid tumors (10). But in CCA treatments, immune checkpoint inhibitors still showed conflicting results (11-16). In several trials testing immunotherapy in anatomically and molecularly unselected CCA patients, immune checkpoint inhibition monotherapy has been disappointing $(17,18)$. Genomic studies have paved the way towards the identification of a wide number of possible targets, the most promising of which are fibroblast growth factor receptor (FGFR) aberrations and isocitrate dehydrogenase (IDH) mutations (19-22). 
The use of liver transplantation to treat iCCA remains controversial owing to high early tumor recurrence rates and poor survival (23). It is contraindicated by the International Liver Cancer Association owing to a paucity of strong published evidence (4). For pCCA, currently, the strongest evidence comes from a multicenter study published in 2018 based on a large number of patients with pCCA $(\mathrm{n}=304)$. The median OS of patients in the liver transplantation group was longer than that in the resection group (32.5 vs. 27.4 months, $\mathrm{p}=0.049)(24)$. Also, a randomized controlled trial comparing liver transplantation with surgical resection is currently ongoing in France (NCT02232932).

Interventional treatment, such as intra-arterial therapies (IAS), ablation, and brachytherapy via iodine-125 ( $\left.{ }^{125} \mathrm{I}\right)$ seed implantation, has developed over the last decades and become an acceptable palliative treatment for patients with unresectable CCA. Active local treatment can help with locoregional control and symptom relief and therefore improves patients' quality of life $(25,26)$. This article aims to explore the role of interventional therapy in the treatment for patients with unresectable CCA.

\section{INTERVENTIONAL TREATMENT FOR CCA}

\section{Intra-Arterial Therapies}

Anatomically, the normal liver receives $70-80 \%$ of its blood supply from the portal vein and $20-30 \%$ from the hepatic artery. Arterially directed therapies, including conventional transarterial chemoembolization (cTACE), drug-eluting bead transarterial chemoembolization (DEB-TACE), and Yttrium-90 radioembolization (Y90-RE), are the most widely applied treatments for unresectable hepatocellular carcinoma (HCC) (27-30). Given that CCA is less vascularized than HCC and contains more fibrous connective tissue, the effects of chemotherapy and drug-eluting beads on tumors may be reduced in theory (31-33). However, the extant literature still suggests that palliative treatment for unresectable CCA is safe and effective for offering a potential survival benefit (34-37).

\section{Hepatic Arterial Infusion Chemotherapy (HAIC)}

Liver-directed therapy via a HAIC pump enables the delivery of high-dose chemotherapy directly into the liver (38). The liver's dual blood supply preferentially delivers high doses of chemotherapeutic agents to the hepatic artery, which supplies nearly all the tumor's blood flow, while blood delivered by the portal vein maintains the health of the non-neoplastic liver parenchyma $(39,40)$. Since the liver clears chemotherapy via first-pass metabolism, this approach diminishes systemic toxic effects (38). Given that advanced disease within the liver accounts for most unresectable cases, continuous HAIC is particularly well suited to cancers in the liver. Using floxuridine, a precursor of fluorouracil and the most active agent, in HAIC is helpful for achieving much higher tumor drug levels compared with systemic administration $(41,42)$.

\section{iCCA}

In 2011, Inaba et al. conducted a phase I/II study to ascertain the recommended dose of hepatic arterial infusion using gemcitabine (GEM) for iCCA (JIVROSG) (43). Dose-limiting toxicity and recommended dose of hepatic arterial infusion of GEM were determined as the primary endpoint. For a sample size of 13 patients who failed to reach the primary endpoint, none of them achieved complete response (CR), while one patient achieved partial response (PR), eight achieved stable disease (SD), and four achieved progressive disease (PD). The study could not prove improvement in test results using HAIC, but it demonstrated an acceptable disease control rate (DCR) Nevertheless, the study had several limitations such as the small sample size and monotherapy of gemcitabine. Ghiringhelli et al. followed with a study to evaluate the efficacy and tolerability of HAIC with gemcitabine plus oxaliplatin on unresectable iCCA, resulting in an overall response rate (ORR) of $66 \%$ and tumor control in $91 \%$ of the patients (44). The median progressionfree survival (PFS) and OS were 9.2 and 20 months, respectively. In 2014, Kasai et al. reported a study that involved 20 patients with advanced iCCA for evaluating HAIC using 5-fluorouracil (5-FU) combined with subcutaneous administration of pegylated interferon $\alpha$-2b (45). The 1 - and 2-year survival rates were 53.7 and $14.3 \%$, respectively. The median OS was 14.6 months. Konstantinidis and colleagues compared the outcomes of patients with unresectable iCCA treated with HAIC plus systemic chemotherapy (SYS) with those treated with SYS alone (46). Disease was confined to the liver in 104 patients who underwent combination therapy of HAIC plus SYS $(n=78)$ or SYS alone $(n=26)$. The ORR in the combined group was better than that in the group receiving SYS alone, although this did not reach statistical significance (59 vs 39\%, $P=0.11)$. Median OS for the combined group was longer than that of the patients who received SYS alone (30.8 vs 18.4 months, $P<0.001)$. Recently, Cercek et al. reported the results of HAIC floxuridine plus systemic administration of gemcitabine and oxaliplatin in patients with unresectable iCCA treated at two medical centers (38). In this single-arm clinical trial including 38 patients, the median PFS was 11.8 months with a 6 -month PFS rate of $84.1 \%$. The median OS was 25.0 months, and the 1-year OS rate reached $89.5 \%$. These studies suggest that HAIC appears to be highly active and tolerable in patients with unresectable iCCA. It offers the best outcomes in terms of tumor response and survival. Further evaluation is warranted to determine whether HAIC should be incorporated into first-line treatment for patients with unresectable iCCA.

\section{eCCA}

Due to its difficulty in visualizing tumor vascularity and tumor stain on hepatic arterial angiographic images, pCCA has been paid little attention to. To evaluate the efficacy and safety of HAIC of oxaliplatin and 5-FU for pCCA, Wang et al. conducted a prospective phase II study (47). The ORR reached $67.6 \%$, which was much higher than expected. DCR of $89.2 \%$ was also higher than that from previously reported systemic chemotherapy. The median PFS, local PFS, and OS were 12.2, 25.0, and 20.5 months, respectively. However, very few reports have been published, and more trials are needed to further investigate these results. 


\section{Conventional Transcatheter Arterial Chemoembolization iCCA}

Typically, the majority of implementation researches on iCCA were retrospective due to the rarity of this disorder. Among the limited prospective studies, Kiefer et al. reported a two-center study (48). Sixty-two patients with unresectable iCCA were treated with CTACE using cisplatin, doxorubicin, and mitomycin mixed with polyvinyl alcohol particles. Imaging assessments were performed every 3 months. The results showed that median OS from first time of diagnosis was 20 months. The 1-, 2-, and 3-year survival rates of patients were 75,39 , and $17 \%$, respectively. For patients treated with TACE plus systemic chemotherapy, median OS was 28 months, and DCR was $76 \%$.

In another study conducted by $\mathrm{Li}$ et al., the established prognostic nomogram (iCCA nomogram) was used to perform survival risk stratification (8). A total of 553 patients who underwent hepatectomy for iCCA between January 2008 and February 2011 were included (49). Of these patients, 122 were treated with adjuvant TACE. In the whole cohort, the 5-year recurrence and $\mathrm{OS}$ rates between the TACE and non-TACE groups were significantly different (5-year recurrence: 72.9 vs 78.1\%; OS: 38.4 vs 29.7\%). According to survival risk stratification generated by the iCCA nomogram, only those in the lowest tertile (nomogram scores $\geq 77$ ) benefited from adjuvant TACE (TACE vs non-TACE groups: 90.4 vs $95.9 \%$ for 5-year recurrence, 21.3 vs $6.2 \%$ for 5-year OS). The study suggests the potential of the established prognostic nomogram as a clinical predictor of whether patients with iCCA can benefit from adjuvant TACE following liver resection.

Another multicentric retrospective study between 2014 and 2017 analyzed 335 patients in 12 centers (50). The median OS of patients in the TACE plus surgery group was longer than that of patients in the surgery group (63 vs 18 months, $P=0.041$ ). According to the TNM staging, stage II/III patients were able to benefit from TACE after surgery $(P=0.021)$. Subgroups stratified by risk factors showed that only adjuvant TACE following liver resection might be suitable for iCCA patients with two or fewer risk factors $(P=0.027)$.

Schernthan et al. presented dual-phase cone-beam computed tomography (DPCBCT) as a new technique for survival analyses in patients with unresectable iCCA (51). This retrospective study included 17 consecutive patients with iCCA who were treated with cTACE. All the patients underwent pre-procedural contrast-enhance magnetic resonance imaging of the liver. In addition, digital subtraction angiography (DSA) and DPCBCT [early-arterial phase (EAP) and delayed-arterial phase (DAP)] were performed immediately before cTACE. Of the 61 iCCA lesions, only $45.9 \%$ were depicted by DSA, whereas EAP- and DAP-CBCT yielded significantly higher detectability rates of 73.8 and $93.4 \%$, respectively $(P<0.01)$. DPCBCT, especially DAPCBCT, significantly improved the detectability of iCCA lesions during CTACE compared to DSA. Additionally, the evidence suggests that iCCA patients would benefit more from cTACE as age increases.

\section{eCCA}

The retrospective study conducted by Zheng et al. involved 72 patients with pCCA. The control group consisted of 35 patients who received simple biliary drainage tube placement and biliary stent implantation, while 37 patients were in the experimental group and treated with cTACE using cisplatin plus gemcitabine (52). Results showed that median OS in the study group was significantly higher than that in the control group (20 vs 10.5 months, $P<0.05$ ), as was patency duration (15.6 vs 7 months, $P<$ $0.05)$. The authors suggest that the combination of cTACE with radiotherapy can significantly prolong the survival of patients with pCCA.

\section{Drug-Eluting Bead-Transcatheter Arterial Chemoembolization}

In CTACE, the oily contrast medium Lipiodol is emulsified with chemotherapeutic drugs and administered into tumor-feeding branches of the hepatic artery (53). Lipiodol and chemotherapeutic drugs may be isolated after injection because emulsification between them is unstable, leading to poor treatment outcomes. DEB-TACE has been promoted to improve tumor drug concentrations and to enhance its antitumor efficacy without increasing the risk of systemic toxicity (54). To our knowledge, the use of DEB-TACE in treating eCCA has not yet been reported, so this review mainly focuses on the response of iCCA patients.

\section{iCCA}

Aliberti et al. reported a prospective research on DEB-TACE loaded with doxorubicin for the treatment of unresectable iCCA (55). The tumor response for the whole sample of 127 patients was PR in 19 (15\%) patients, SD in 101 (80\%), and PD in 7 (5\%) patients 3 months after therapy. The DCR was 95 and $85 \%$ in the $\mathrm{DEB}$ and PEG groups, respectively. In a small retrospective study with 20 patients, Poggi et al. treated nine iCCA patients with chemotherapy plus DEB-TACE, and carried out a retrospective comparison with 11 patients treated with chemotherapy only (56). Approximately $44 \%$ of patients in the chemotherapy plus DEB-TACE group achieved PR, and 56\% achieved SD. The median OS was 30 months for the chemotherapy plus DEBTACE groups and 12.7 months for chemotherapy-only patients $(P=0.004)$, respectively. Propensity score-matched analysis showed a significant survival benefit for patients who received chemotherapy plus DEB-TACE compared to those undergoing chemotherapy only. Recently, a prospective multicenter study including 37 patients with iCCA was conducted (57). For patients treated with DEB-TACE loaded with Adriamycin, about $8.1 \%$ of them achieved CR, while $59.5 \%$ achieved PR. This treatment provided an ORR of approximately $67.6 \%$ and a median OS of 376 days. Furthermore, the multivariate Cox proportional hazards model identified macrovascular invasion (portal or hepatic vein tumor thrombi) as a risk factor for poor prognosis in iCCA patients. In the case of mild adverse events such as abnormal liver function, DEB-TACE is well tolerated by patients. Eighty-eight unresectable iCCA patients who received DEB-TACE treatment with CalliSpheres (CSM) were retrospectively enrolled in a recent study (58). The tumor 
response of the whole sample of 88 patients was PR in 58 (65.9\%) patients, SD in 19 (21.6\%), and PD in $11(12.5 \%)$ at 1 month after therapy. The median PFS and OS were 3.0 months and 9.0 months, respectively. DEB-TACE with CSM is safe, effective, and well tolerated for unresectable iCCA patients, providing a high DCR, low complication rate, and relative benefit in terms of survival.

\section{Radioembolization}

Y90-RE has been demonstrated to provide long-term survival benefits for patients with primary or secondary liver tumors (59). Microspheres impregnated with Y90 are delivered through the hepatic artery to tumors with preferential blood flow. After Y90containing microspheres go through arterial catheters to the hepatic arteries that feed the tumor, it enables a high radiation dose in the tumor with minimal exposure to normal tissues.

The clinical importance and efficacy of Y90-RE in treating HCC patients are widely documented in the international literature $(60,61)$. However, very limited data are available on the use of Y90-RE in CCA patients.

In 2008, Ibrahim et al. was the first to research Y90-RE in treating patients with iCCA (62). Twenty-four patients with histologically proven iCCA were treated. Based on imaging follow-up of 22 patients, 6 (27\%), 15 (68\%), and 1 (5\%) patient achieved PR, SD, and PD, respectively. The median OS for the entire cohort was 14.9 months. This research suggests that Y90RE may be a therapeutic option for unresectable iCCA. Hoffman et al. reviewed 33 patients with unresectable iCCA who were treated with Y90-RE (63). Overall, 12 patients achieved PR, 17 achieved SD, and 5 achieved PD after 3 months. The median OS was 22 months. Median time to progression was 9.8 months. In regard to grading criteria after Y90-RE, Camacho et al. evaluated patient response to $\mathrm{Y} 90-\mathrm{RE}$ using the modified response evaluation criteria in solid tumors (mRECIST) and the European association for the study of the liver (EASL) guidelines (64). The prospective study included 21 patients with a median OS of 16.3 months. The efficacy of mRECIST and EASL was 56.2 and 50\%, respectively, which were much higher than $6.2 \%$ generated by RECIST $(P<0.001)$. This research may propose an effective and feasible method for the assessment of iCCA patients treated with Y90-RE.

In general, regarding Y90-RE for treatment of iCCA, theexisting literature suggests that the treatment is effective and relatively safe. Additionally, it is well tolerated by patients with aggressive invasion. A substantial number of studies indicate that the ORR of Y90-RE in iCCA patients range from 24 to $82.3 \%$ (Tables 1, 2).

\section{Ablation}

Ablation has been a treatment option for HCC for advantages of minimal invasion, simple, maneuverable, low risk, and high costeffectiveness (65-68). It is cheaper and quicker to perform than resection and reduces hospital admission (69). In 2019, Yousaf et al. reported a meta-analysis on ablative therapies treating iCCA (70). A total of 10 studies were included, yielding an aggregate of 206 patients and 320 tumors. The median OS ranged

TABLE 1 | Study design and characteristics within included studies for IAS.

\begin{tabular}{|c|c|c|c|c|c|c|c|}
\hline Investigators & $\begin{array}{l}\text { No. of } \\
\text { patients }\end{array}$ & Study interval & Design & Diagnosis & Control group & Experimental group & Ref. \\
\hline Inaba (2011) & 13 & 2004-2005 & Prospective & Unresectable iCCA & / & HAIC (GEM) & $(43)$ \\
\hline Ghiringhell (2013) & 12 & 2008-2013 & Retrospective & Unresectable iCCA & / & HAIC (GEM plus oxaliplatin) & (44) \\
\hline Kasai (2014) & 20 & $2008-2013$ & Prospective & Unresectable iCCA & / & $\begin{array}{l}\text { HAIC (5-FU plus subcutaneous PEG-IFN } \\
\alpha-2 b)\end{array}$ & $(45)$ \\
\hline $\begin{array}{l}\text { Konstantinidis } \\
(2015)\end{array}$ & 104 & 2000-2012 & Retrospective & Unresectable iCCA & $\begin{array}{l}\text { Systemic chemotherapy } \\
\text { alone }\end{array}$ & HAIC plus systemic chemotherapy & $(46)$ \\
\hline Cercek (2019) & 38 & 2013-2019 & Prospective & Unresectable iCCA & / & $\begin{array}{l}\text { HAIC (floxuridine) plus systemic } \\
\text { chemotherapy (gemcitabine and oxaliplatin) }\end{array}$ & (38) \\
\hline Wang (2016) & 37 & 2012-2015 & Prospective & Unresectable pCCA & / & HAIC (oxaliplatin plus 5-FU) & $(47)$ \\
\hline Kiefer (2010) & 62 & N/A & Retrospective & Unresectable iCCA & / & $\begin{array}{l}\text { CTACE (cisplatinum, doxorubicin, mitomycin- } \\
\text { C, ethiodol, and polyvinyl alcohol particles) }\end{array}$ & $(48)$ \\
\hline Li (2015) & 553 & 2008-2011 & Retrospective & $\begin{array}{l}\text { iCCA after } \\
\text { hepatectomy }\end{array}$ & Non-cTACE $(n=431)$ & CTACE $(n=122)$ & $(49)$ \\
\hline Wang (2020) & 335 & 2014-2017 & Retrospective & $\begin{array}{l}\text { iCCA after } \\
\text { hepatectomy }\end{array}$ & Non-cTACE $(n=296)$ & cTACE $(n=39)$ & $(50)$ \\
\hline Zheng (2019) & 72 & 2014-2018 & Retrospective & Unresectable pCCA & $\begin{array}{l}\text { Biliary drainage tube } \\
\text { placement and biliary } \\
\text { stent implantation ( } n= \\
\text { 35) }\end{array}$ & $\begin{array}{l}\text { CTACE (gemcitabine and cisplatin) and } \\
\text { extracorporeal radiotherapy after biliary } \\
\text { drainage or biliary stent implantation }(n=37)\end{array}$ & $(52)$ \\
\hline Aliberti (2017) & 127 & 2000-2016 & Prospective & Unresectable iCCA & $\mathrm{N} / \mathrm{A}$ & DEB-TACE loaded with doxorubicin & $(55)$ \\
\hline Poggi (2009) & 20 & 2005-2008 & Retrospective & Unresectable iCCA & Chemotherapy & DEB-TACE loaded with oxaliplatin & $(56)$ \\
\hline Luo (2020) & 37 & 2015-2016 & Prospective & Unresectable iCCA & $\mathrm{N} / \mathrm{A}$ & DEB-TACE loaded with Adriamycin & $(57)$ \\
\hline Zhou (2020) & 88 & 2015-2018 & Retrospective & Unresectable iCCA & $\mathrm{N} / \mathrm{A}$ & DEB-TACE treatment with epirubicin & $(58)$ \\
\hline Ibrahim (2008) & 24 & 2004-2008 & Prospective & Unresectable iCCA & $\mathrm{N} / \mathrm{A}$ & Y90-RE & $(62)$ \\
\hline Hoffmann (2011) & 33 & 2007-2010 & Retrospective & Unresectable iCCA & $\mathrm{N} / \mathrm{A}$ & Y90-RE & (63) \\
\hline
\end{tabular}

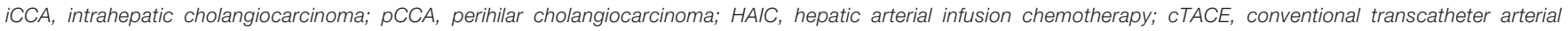
chemoembolization; DEB-TACE, drug-eluting bead transcatheter arterial chemoembolization; Y90-RE, yttrium-90 radioembolization; GEM, gemcitabine; 5-FU, 5-fluorouracil; PEG-IFN, pegylated interferon. 
TABLE 2 | Results and adverse events within included studies for IAS.

\begin{tabular}{|c|c|c|c|c|c|}
\hline Investigators & $\begin{array}{c}\text { ORR } \\
\text { (EG or EG vs CG) }\end{array}$ & $\begin{array}{c}\text { DCR } \\
\text { (EG or EG vs CG) }\end{array}$ & $\begin{array}{c}\text { PFS } \\
\text { (EG or EG vs CG) }\end{array}$ & $\begin{array}{l}\text { Median OS } \\
\text { (EG or EG vs CG) }\end{array}$ & Adverse events (grade III/IV) \\
\hline Inaba (43) & $\begin{array}{c}7.7 \%(95 \% \mathrm{Cl} \\
0.2-36.0 \%)\end{array}$ & $\begin{array}{c}69 \%(95 \% \mathrm{Cl} \\
38.6-90.9 \%)\end{array}$ & $\mathrm{N} / \mathrm{A}$ & $\begin{array}{l}389 \text { d }(95 \% \mathrm{Cl} \\
158-620)\end{array}$ & $\begin{array}{l}\text { Neutropenia }(n=2) \text {, elevated GGT }(n=1) \text {, elevated AST } \\
(n=1) \text {, elevated ALT }(n=1) \text {, elevated bilirubin plus PVTT } \\
(n=1)\end{array}$ \\
\hline Ghiringhell (44) & $\begin{array}{l}66.6 \%(95 \% \mathrm{Cl} \\
29-100 \%)\end{array}$ & $\begin{array}{c}91 \%(95 \% \mathrm{Cl} \\
45-100 \%)\end{array}$ & $\begin{array}{l}9.2 \mathrm{mo}(95 \% \mathrm{Cl} \\
5.1-29.4)\end{array}$ & $\begin{array}{l}20.3 \mathrm{mo}(95 \% \mathrm{Cl} \\
13.2-49.7)\end{array}$ & $\begin{array}{l}\text { Neutropenia }(n=2) \text {, thrombocytopenia }(n=2) \\
\text { oxaliplatin allergy }(n=2)\end{array}$ \\
\hline Kasai (45) & $60 \%$ & $90 \%$ & $\begin{array}{l}8.0 \mathrm{mo}(95 \% \mathrm{Cl} \\
3.1-14.5)\end{array}$ & $\begin{array}{l}14.6 \mathrm{mo}(95 \% \mathrm{Cl} \\
5.5-16.8)\end{array}$ & $\begin{array}{l}\text { Leukopenia }(n=2) \text {, thrombocytopenia }(n=2) \text {, anemia } \\
(n=2)\end{array}$ \\
\hline Konstantinidis (46) & $\begin{array}{c}59 \text { vs } 39 \% \\
P=0.11\end{array}$ & N/A & N/A & $\begin{array}{l}30.8 \text { vs } 18.4 \mathrm{mo} \\
(P<.001)\end{array}$ & None \\
\hline Cercek (38) & $58 \%$ & $84 \%$ & $\begin{array}{l}11.8 \mathrm{mo}(1 \text {-sided } \\
90 \% \mathrm{Cl}, 11.1)\end{array}$ & $\begin{array}{l}25.0 \mathrm{mo}(95 \% \mathrm{Cl}, \\
20.6-\text { not reached })\end{array}$ & $\begin{array}{l}4 \text { patients }(11 \%) \text { had grade } 4 \text { toxic effects: portal } \\
\text { hypertension }(n=1) \text {, gastroduodenal artery aneurysm } \\
(n=2) \text {, infection in the pump pocket }(n=1)\end{array}$ \\
\hline Wang (47) & $67.60 \%$ & $89.20 \%$ & $\begin{array}{l}12.2 \mathrm{mo}(95 \% \mathrm{Cl} \\
6.60-17.83)\end{array}$ & $\begin{array}{l}20.5 \mathrm{mo}(95 \% \mathrm{Cl} \\
11.12-29.88)\end{array}$ & $\begin{array}{l}\text { Severe anemia (16.2\%), leukopenia ( } 10.8 \%) \text {, } \\
\text { thrombocytopenia (13.5\%), Grades } 3 \text { and } 4 \text { liver enzyme } \\
\text { elevation ( } 8.1 \%) \text {, severe abdominal pain }(5.4 \%)\end{array}$ \\
\hline Kiefer (48) & $11 \%$ & $76 \%$ & $8 \mathrm{mo}$ & $20 \mathrm{mo}$ & $\begin{array}{l}\text { Pulmonary edema and elevated cardiac enzymes } \\
(n=1) \text {, pulmonary infarct }(n=1) \text {, severe } \\
\text { postembolization syndrome }(n=1) \text {, hyperglycemia } \\
(n=1) \text {, acute renal failure and dehydration }(n=1)\end{array}$ \\
\hline Li (49) & $\mathrm{N} / \mathrm{A}$ & $\mathrm{N} / \mathrm{A}$ & 22.0 vs $14.3 \mathrm{mo}$ & 27.6 vs 20.4 mo & None \\
\hline Wang (50) & $\mathrm{N} / \mathrm{A}$ & $\mathrm{N} / \mathrm{A}$ & $\begin{array}{l}50 \text { vs } 10 \mathrm{mo} \\
P=0.022\end{array}$ & $\begin{array}{l}63.0 \text { vs } 18.0 \mathrm{mo} \\
P=0.041\end{array}$ & None \\
\hline Zheng (52) & $\mathrm{N} / \mathrm{A}$ & N/A & $10.5 \mathrm{mo}$ & $20.0 \mathrm{mo}$ & Biliary hemorrhage and cholangitis \\
\hline Aliberti (55) & $15 \%$ & $95 \%$ & $\mathrm{~N} / \mathrm{A}$ & $\begin{array}{l}14.53 \mathrm{mo}(95 \% \mathrm{Cl} \\
9.17-15.23)\end{array}$ & Nausea/vomiting (24\%), fever (7\%), pain (7\%) \\
\hline Poggi (56) & $44 \%$ & $100 \%$ & $\begin{array}{l}8.4 \text { vs } 2.9 \mathrm{mo} \\
P=0.1\end{array}$ & $\begin{array}{l}30 \text { vs } 12.7 \mathrm{mo} \\
P=0.004\end{array}$ & $\begin{array}{l}\text { Abdominal pain ( } 24 \% ; 28 / 67) \text {, cholangitis G3 }(3 \% ; 2 / 67) \text {, } \\
\text { hypertensive crisis G3 }(3 \% ; 2 / 67)\end{array}$ \\
\hline Luo (57) & $67.60 \%$ & $91.90 \%$ & N/A & $\begin{array}{l}376 \text { d }(95 \% \mathrm{Cl} \\
341-412 \mathrm{~d})\end{array}$ & None \\
\hline Zhou (58) & $65.90 \%$ & $87.50 \%$ & 3 (95\% Cl, 2.5-3.5) & 9 (95\% Cl, 7.0-11.0) & None \\
\hline Ibrahim (62) & $27 \%$ & $95 \%$ & N/A & $14.9 \mathrm{mo}$ & $\begin{array}{l}\text { Albumin toxicities }(17 \%) \\
\text { Bilirubin toxicity }(4 \%)\end{array}$ \\
\hline Hoffmann (63) & $36.40 \%$ & $87.90 \%$ & $9.8 \mathrm{mo}$ & $22 \mathrm{mo}$ & No clinical relevant acute or delayed toxicities \\
\hline
\end{tabular}

ORR, overall response rate; DCR, disease control rate; PFS, progression-free survival; OS, overall survival; CG, control group; EG, experimental group; 95\% CI, 95\% confidence interval; GGT, gamma-glutamyl transpeptidase; AST, aspartate aminotransferase; ALT, alanine aminotransferase; PVTT, portal vein tumor thrombosis.

from 8.7 to 52.4 months. Pooled 1-, 3-, and 5-year survival rates were 76,33 , and $16 \%$, respectively. Ablative therapies display promising potential as treatment modalities for CCA.

\section{Radiofrequency Ablation (RFA)}

Radiofrequency ablation is the most studied energy-based ablative method. It utilizes high-frequency alternating electric current to cause cell death by heating tissue through rapid electron vibration that generates frictional heat (71). RFA has been applied to treat esophageal and primary or malignant liver tumors. The length of hospital stay, treatment cost, and risk of complications tend to be lower with RFA than with surgery $(72,73)$.

\section{iCCA}

Seven studies and 84 patients were included in a recent metaanalysis to assess the efficacy and safety of RFA in treating iCCA (74). The pooled 1-, 3-, and 5-year survival rate was 82,47 , and $24 \%$, respectively. The authors conclude that RFA is a locoregional treatment option that prolongs survival rates in patients with iCCA who are ineligible for surgery.

The efficacy of RFA is closely associated with tumor size. Carrafiello et al. obtained complete necrosis of all four tumors smaller than $4 \mathrm{~cm}$. However, they were unable to achieve the same result in the two patients with tumors larger than $5 \mathrm{~cm}$ even though pre-interventional TACE was performed to increase the area of ablation (75). As a result, residual tumors were observed in these two patients with larger tumors (5 and $5.8 \mathrm{~cm}$ in diameter). All patients could tolerate the procedure, and no major complication was identified. In Kim et al.'s study on primary iCCA treated with RFA, technical effectiveness was achieved in all 11 patients with tumors $<5 \mathrm{~cm}$ but in none of the patients with larger lesions (76). Giorgi et al. performed RFA on 10 patients with unresectable iCCA and proved its effectiveness for lesions smaller than $3.4 \mathrm{~cm}$ (77). However, for those larger than $4 \mathrm{~cm}$, RFA failed to provide survival benefit. Recently, Brandi et al. reported a retrospective study including 29 patients with 117 nodules. At a median follow up of 39.9 months, median OS was 27.5 months. The 1-, 2-, and 4- years of OS was 89, 45 , and $11 \%$, respectively. It indicates that tumor size $\geq 20 \mathrm{~mm}$ was associated with lower PFS, representing a potential useful threshold value (78). To be concluded, for smaller iCCA lesions, percutaneous RFA should have a higher chance of success.

RFA guided by endoscopic retrograde cholangiopancreatography (ERCP) in treating iCCA and other intraductal malignancies is 
gaining popularity (79). Several studies demonstrate that patients receiving RFA with stenting maintained stent patency at 30 days, deeming endobiliary RFA to be a safe treatment $(80,81)$.

\section{eCCA}

Wang et al. treated nine patients with unresectable Bismuth types III and IV hilar cholangiocarcinoma using percutaneous intraductal RFA combined with metal stent placement after percutaneous transhepatic cholangial drainage (82). Median stent patency from the time of the first RFA and median OS were 100 days and 5.3 months, respectively. For dCCA, Wu et al. investigated the clinical efficacy of intraductal RFA in patients with dCCA (83). The RFA group had a longer median stent patency than the control group $(P=0.001)$. Prolonged stent patency, better functional status, and improved quality of life, which are all important clinical endpoints, were observed in patients treated with intraductal RFA.

\section{Microwave Ablation (MWA)}

MWA describes a thermoablative, minimally invasive technique for treatment of tumors. Its efficiency in solid tumors has been widely reported over the years and is concerned with many theoretical advantages, such as shorter ablation time, higher ablation temperature, shorter operative time, and larger ablation zone (84-86). To the best of our knowledge, there is no relevant literature on the use of MWA in treating patients with eCCA.

\section{iCCA}

A prospective study in 2011 involved 15 unresectable iCCA patients (87). All patients received ultrasound-guided percutaneous MWA. The rates for ablation success, technique effectiveness, and local tumor progression were $91.7 \%$ (22/24), 87.5\% (21/24), and 25\% (6/24), respectively. Minor complications and side effects were experienced by most patients, which subsided with supportive treatment. A retrospective analysis conducted by Zhang et al. showed that in a cohort of 107 patients (88), the frequency of major complications was $2.8 \%$ and that of procedure-related deaths was $0 \%$. The median PFS and median OS were 8.9 months and 28.0 months, respectively. The 1-, 3-, and 5-year OS rates were 93.5, 39.6, and $7.9 \%$, respectively. To compare the effectiveness of the two therapeutic methods (MWA and surgery), Xu et al. reported a retrospective study with 121 patients included (89). Fifty-six patients were treated with MWA, while 65 underwent surgery. The OS and RFS after MWA were comparable to those after surgery ( $P=0.405$ and $P=0.589$, respectively). The estimated 5year OS rate was $23.7 \%$ after MWA and $21.8 \%$ after surgery; for RFS, the estimated 3-year RFS rate was 33.1\% after MWA and 30.6\% after surgery. Major complication rate in the surgery group was higher than that in the MWA group $(P<0.001)(13.8 v s 5.3 \%)$. The authors suggest that MWA produces oncologic outcomes comparable to those of surgery and could be a safe and effective treatment for recurrent iCCA after hepatectomy.

\section{Irreversible Electroporation (IRE)}

In 2005, IRE was first introduced as a non-thermal ablation technique for tumor ablation (90). The electrical pulses permeabilize the lipid bilayer of the cell membrane, thereby disrupting intracellular homeostasis and inducing apoptosis (91-93). In contrast to other thermal ablation techniques, IRE work through a high-voltage pulsed electric field without destructing the extracellular matrix (94). Various retrospective studies have demonstrated the safety of peribiliary tumor ablation with $\operatorname{IRE}(95,96)$, and catheter-directed IRE in the swine bile duct was designed for biliary malignancies (97). IRE is a relatively new technology and therefore, very few studies have been conducted so far.

\section{iCCA}

The very few studies on iCCA include Belfiore et al.'s investigation which assessed the safety, feasibility, and efficacy of IRE in treating CCA (98). A total of 15 patients with unresectable CCA (eight with iCCA and seven with pCCA) were enrolled in this prospective study. The imaging follow-up showed local disease control with a decrease in the entire volume of the lesion and a further reduction in the densitometric values. The mean survival was 18 months (95\% CI, 18.8-36.7 months).

\section{eCCA}

In 2018, Martin et al. conducted a study to investigate the safety and efficacy of IRE in treating obstructive jaundice in advanced pCCA (99). Twenty-six patients underwent IRE for pCCA after percutaneous transhepatic biliary drainage (PTBD) replacement. After treatment, the median time to PTBD removal was 122 days (ranging 0-305 days), and the median catheter-free time before requiring PTBD replacement was 305 days (ranging 92-458 days). Authors suggest that in patients with pCCA who present with obstructive jaundice, IRE can be used to increase catheter-free days and to optimize overall quality of life. To assess the safety and efficacy of IRE for unresectable pCCA, Hsiao et al. treated nine patients from two medical centers in Asia using IRE (100). The median OS was 26 months, and the median PFS was 18 months. These studies show that IRE ablation of unresectable CCA involving vital structures is a safe and feasible primary treatment for local tumor control and is effective in prolonging survival.

By far, multicenter large prospective studies are still lacking. However, a randomized controlled trial in a multicenter phase I/II safety and feasibility study is underway (101) (Tables 3, 4).

\section{Cryoablation}

Cryoablation produces intra- and extracellular ice crystals to cause dehydration and osmotic pressure changes of the cells. These changes induce the damage of cell membrane and organelle and leads to cell death eventually.

Currently, few studies have evaluated the effectiveness of cryoablation for the treatment of CCA. In a retrospective study, 299 hepatic tumors were included (102). The technical success rate was $94.6 \%(279 / 295)$. The technique efficacy rate was $89.5 \%(231 / 258)$ and was greater for tumors smaller than $4 \mathrm{~cm}(93.4 \% ; 213 / 228)$ than for larger tumors $(60.0 \% ; 18 / 30)$ $(P<0.0001)$. However, only six patients in this study had CCA. Another study on cryoablation involved 39 hepatic tumors in total, but only three were iCCA. These studies suggest that cryoablation provides an option for hepatic tumors, but compelling evidence for CCA remains insufficient. Further 
TABLE 3 | Study design and characteristics within included studies for ablation.

\begin{tabular}{|c|c|c|c|c|c|c|c|c|c|}
\hline Investigators & No. of patients & No. of tumors & Tumor size & Study interval & Design & Diagnosis & CG & EG & Ref. \\
\hline Carrafiello (2010) & 6 & 7 & $1-5.8 \mathrm{~cm}$ & 2004-2008 & Prospective & Unresectable iCCA & / & RFA & (75) \\
\hline Kim (2011) & 13 & 17 & $0.8-8 \mathrm{~cm}$ & 2000-2009 & Retrospective & Unresectable iCCA & / & RFA & (76) \\
\hline Giorgi (2011) & 10 & 12 & $2.4-7.0 \mathrm{~cm}$ & 2003-2010 & Retrospective & Unresectable iCCA & / & RFA & (77) \\
\hline Brandi (2020) & 29 & 117 & $0.5-4.8 \mathrm{~cm}$ & 2014-2019 & retrospective & unresectable iCCA & / & RFA & (78) \\
\hline Yu (2011) & 15 & 24 & $1.3-9.9 \mathrm{~cm}$ & 2006-2010 & Prospective & iCCA & / & MWA & (87) \\
\hline Zhang (2017) & 107 & 171 & $<5 \mathrm{~cm}$ & 2009-2016 & Retrospective & Recurrent iCCA & / & MWA & (88) \\
\hline Xu (2019) & 121 & 136 & $<5$ & 2011-2017 & Retrospective & Recurrent iCCA & $\mathrm{SR}(\mathrm{n}=65)$ & MWA $(n=56)$ & (89) \\
\hline \multirow[t]{2}{*}{ Belfiore (2020) } & 8 & 8 & $5.6-267.2 \mathrm{~cm}^{3}$ & 2015-2019 & Prospective & Unresectable iCCA & / & IRE & (98) \\
\hline & 7 & 7 & $23.4-159.5 \mathrm{~cm}^{3}$ & 2015-2019 & Prospective & Unresectable pCCA & & & \\
\hline
\end{tabular}

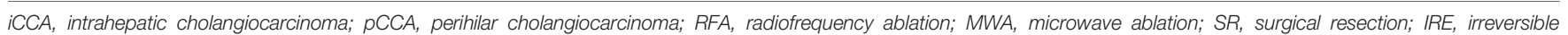
electroporation; CG, control group; EG, experimental group.

TABLE 4 | Results and adverse events within included studies for ablation.

\begin{tabular}{|c|c|c|c|c|c|c|}
\hline Investigators & Follow-up (mo) (range) & Technical success & $\begin{array}{c}\text { Technical } \\
\text { effectiveness }\end{array}$ & $\begin{array}{c}\text { PFS } \\
\text { (EG or EG vs CG) }\end{array}$ & $\begin{array}{c}\text { Median OS } \\
\text { (EG or EG vs CG) }\end{array}$ & Adverse events (grade III/IV) \\
\hline Carrafiello (75) & Mean 17.5 (13-21) & / & 66 & / & / & None \\
\hline $\operatorname{Kim}(76)$ & $\begin{array}{c}\text { Median } 19.5 \\
(3.3-82.1)\end{array}$ & $88 \%$ & $88 \%$ & $32.2 \mathrm{mo}$ & $38.5 \mathrm{mo}$ & Liver abscess $(n=1)$ \\
\hline Giorgi (77) & Median 19.5 (9-64) & / & 66 & / & / & None \\
\hline Yu (87) & Mean $12.8(4-31)$ & $91.70 \%$ & $87.50 \%$ & / & $10 \mathrm{mo}$ & $\begin{array}{l}\text { Liver abscess (13.3\%), needle seeding } \\
(6.7 \%)\end{array}$ \\
\hline Zhang (88) & $\begin{array}{c}\text { Median } 20.1 \\
(2.8-63.5)\end{array}$ & $100 \%$ & $93.00 \%$ & $\begin{array}{c}8.9 \mathrm{mo}(95 \% \mathrm{Cl} \\
6.5-11.3)\end{array}$ & $\begin{array}{c}28 \mathrm{mo}(95 \% \mathrm{Cl} \\
23.7-32.2)\end{array}$ & $\begin{array}{l}\text { Pleural effusion (1.9\%), liver abscess } \\
(0.9 \%)\end{array}$ \\
\hline Xu (89) & / & 100 vs $100 \%$ & 100 vs $100 \%$ & $P=0.589$ & $\begin{array}{c}31.3 \text { vs } 29.4 \\
P=0.405\end{array}$ & $\begin{array}{l}\text { MWA: hepatic failure }(n=1) \text {, liver } \\
\text { abscesses }(n=2) \text {, ascites }(n=1) \\
\text { SR: hepatic failure }(n=2) \text {, ascites }(n=6) \text {, } \\
\text { jaundice }(n=3) \\
\text { MWA vs SR: } 5.3 \text { vs } 13.8 \%(P<0.001)\end{array}$ \\
\hline Belfiore (98) & $(6-48)$ & $100 \%$ & $100 \%$ & / & $\begin{array}{c}18 \mathrm{mo}(95 \% \mathrm{Cl} \\
18.8-36.7)\end{array}$ & None \\
\hline
\end{tabular}

PFS, progression-free survival; OS, overall survival; MWA, microwave ablation; SR, surgical resection; CG, control group; EG, experimental group.

studies focusing on cryoablation of CCA may help demonstrate its role in a select group of patients where resection or other ablative therapies are not possible (103).

\section{Brachytherapy $\left({ }^{125}\right.$ I Seed Implantation/ ${ }^{125}$ I Seeds Combined With Biliary Stenting)}

In 2006, Nag et al. reported a study of 64 patients with unresectable primary and metastatic liver tumors from 1989 to 2002 (104). Patients were treated with ${ }^{125} \mathrm{I}$ brachytherapy of $160 \mathrm{~Gy}$. The overall 1-, 3-, and 5-year actuarial intrahepatic local control rates were 44, 22 , and $22 \%$, respectively, with a median time to recurrence of 9 months (95\% CI, 6-12 months). The 1-, 3-, and 5-year actuarial OS rates were 73, 23, and 5\%, respectively (median, 20 months; $95 \%$ CI, 16-24). Back to that time, primary liver carcinoma widely included HCC and intrahepatic bile duct carcinoma. However, this study still shows potential benefit for iCCA patients.

When CCA causes malignant biliary obstruction, percutaneous transhepatic-cholangiodrainage and percutaneous biliary stent (PTBS) can mitigate the complications of further biliary obstruction, reduce serum bilirubin, and improve quality of life. As an effective method of palliation, PTBS leads to a shorter hospital stay and decreased risk of postoperative complications compared with surgery (105). However, stents can become occluded due to epithelial hyperplasia, tumor ingrowth or overgrowth, biofilm deposition, and sludge formation; thus, this process may need to be repeated several times. In contrast, ${ }^{125} \mathrm{I}$ seeds combined with biliary stenting can relieve stent blockage significantly $(106,107)$. In 2018, Zhu et al. reported a randomized, open-label trial of 328 participants with unresectable malignant biliary obstruction at 20 centers in China (108). The participants were allocated into the ${ }^{125} \mathrm{I}$ seed-loaded irradiation stent group (ISG) or the uncovered selfexpandable metallic stent (USG). The first quartile stent patency time (when $25 \%$ of the patients experienced stent restenosis) was 212 days for ISG and 104 days for USG. ISG was linked with a significant decrease in the rate of stent restenosis ( 9 vs 15\% at 90 days; 16 s $27 \%$ at 180 days; 21 vs $33 \%$ at 360 days; $P=.010)$. Longer median OS was achieved in ISG (202 days $v s 104$ days; $P=.020$ ). As for technical success rate and the incidence of complications, no significant difference was observed ( 93 vs $95 \%, P=.499 ; 8.5$ vs $7.9 \%$, $P=.841$ ). Compared with separate biliary stents, ${ }^{125}$ I seed-loaded biliary stenting can significantly prolong the survival time, improve the stent patency, and improve the prognoses of CCA patients (109-111).

\section{eCCA}

Cui et al. retrospectively analyzed 73 cases of pCCA patients who underwent PTBS combined with ${ }^{125}$ I seed intracavitary irradiation (112). The serum levels of total bilirubin, direct 
bilirubin, alanine aminotransferase, aspartate aminotransferase, and alkaline phosphatase were significantly reduced, while albumin was significantly increased at 1 and 3 months postoperatively. The median survival time of the cohort was 12 months, and the 1-year survival rate was $53.1 \%$. Recently, Pang et al. retrospectively reviewed 184 patents to compare the efficacy of PTBS only and PTBS combined with ${ }^{125} \mathrm{I}$ particle implantation when treating advanced eCCA (113). Among these patients, 71 received PTBS, and 113 received additional implantation of ${ }^{125} \mathrm{I}$ particles. Jaundice and liver function were significantly improved in all patients, especially in the PTBS $+{ }^{125} \mathrm{I}$ group. There was no significant difference in the risk of postoperative complications between the two groups. Meanwhile, the risk of biliary reobstruction was significantly reduced in the PTBS $+{ }^{125}$ I group $(19.5$ vs $35.2 \%, P=0.017)$. Patients in the PTBS + ${ }^{125}$ I group had a significantly better OS for both pCCA and dCCA. The authors suggest that for patients with advanced eCCA, PTBS combined with ${ }^{125} \mathrm{I}$ particle implantation is superior to PTBS monotherapy in improving liver function, inhibiting biliary reobstruction, and prolonging survival.

\section{DISCUSSION}

In summary, although large-scale randomized controlled trials are relatively sparse, the current literature suggests that palliative local interventional treatment is a safe, effective, and feasible method for unresectable or recurrent CCA after hepatectomy. Also, promising preclinical evidence shows that palliative treatment can significantly prolong survival time and improve quality of life with fewer side effects.

Among various interventional methods, intra-arterial embolotherapy has been widely accepted for its selective targeting precision, which augments drug exposure of tumors localized in the liver without increasing systemic toxicity.

Y90-RE has become increasingly acceptable, while in terms of palliative treatment in CCA, cTACE remains the most common intra-arterial therapy. With few toxic side effects, intra-arterial embolotherapy can be well tolerated.

In HCC, ablation has been considered a first-line therapy in most guidelines around the world. In regard to CCA, some guidelines also suggest that ablation may benefit patients with unresectable CCA. Current studies mostly concentrate on the size of the tumor to be treated. No guidelines have shown a benefit of ablation for management of patients with different

\section{REFERENCES}

1. Benavides M, Anton A, Gallego J, Gomez MA, Jimenez-Gordo A, La Casta A, et al. Biliary Tract Cancers: SEOM Clinical Guidelines. Clin Transl Oncol (2015) 17(12):982-7. doi: 10.1007/s12094-015-1436-2

2. Lendvai G, Szekerczes T, Illyes I, Dora R, Kontsek E, Gogl A, et al. Cholangiocarcinoma: Classification, Histopathology and Molecular Carcinogenesis. Pathol Oncol Res (2020) 26(1):3-15. doi: 10.1007/s12253018-0491-8

3. Cai Y, Cheng N, Ye H, Li F, Song P, Tang W. The Current Management of Cholangiocarcinoma: A Comparison of Current sizes of CCA. However, ablation could be a safe and effective method when surgery is forbidden.

Several studies indicate that after implantation of radioactive ${ }^{125} \mathrm{I}$ particles, the percentages of $\mathrm{CD}^{+} \mathrm{T}, \mathrm{CD}^{+} \mathrm{T}$, natural killer, and regulatory $\mathrm{T}$ cells significantly increased in the peripheral blood of tumor patients. In addition, the concentrations of immunoglobulin (IgM, IgG, and IgA) and complements (C3 and C4) also increased, indicating that ${ }^{125} \mathrm{I}$ particles may stimulate not only cellular immunity but also humoral immunity $(114,115)$. Current evidence suggests that ${ }^{125} \mathrm{I}$ brachytherapy is a promising treatment and deserves more attention to further investigation.

Many studies document the limitations of current observational research, such as single-center, non-randomized, and smallsample-size studies. Therefore, multicenter prospective observational studies are warranted to validate current findings.

In conclusion, compared with systemic treatments such as systemic chemotherapy and radiotherapy, local interventional control treatment for unresectable or recurrent tumors after surgery offers longer OS. On the other hand, local interventional treatment can downstage the tumor and increase the resectability of CCA. Prospective randomized trials are needed to confirm the application range, indications, and target populations who are most likely to benefit from local interventional therapy.

\section{AUTHOR CONTRIBUTIONS}

J-HG, LC, and HL drafted the manuscript. All authors contributed to the article and approved the submitted version.

\section{FUNDING}

This study was supported by National Natural Science foundation of China (81520108015, 81827805, and 81971716) and the Jiangsu Provincial Special Program of Social Program of Social Development (BE2016783 and SBK20190350). The funding sources had no role in writing of the report or decision to submit the paper for publication.

\section{ACKNOWLEDGMENTS}

We would like to thank J-HG and LC for their help during the preparation and revision of the paper.

Guidelines. Biosci Trends (2016) 10(2):92-102. doi: 10.5582/ bst.2016.01048

4. Bridgewater J, Galle PR, Khan SA, Llovet JM, Park JW, Patel T, et al. Guidelines for the Diagnosis and Management of Intrahepatic Cholangiocarcinoma. J Hepatol (2014) 60(6):1268-89. doi: 10.1016/j.jhep.2014.01.021

5. Benson AB, D’Angelica MI, Abbott DE, Abrams TA, Alberts SR, Anaya DA, et al. Guidelines Insights: Hepatobiliary Cancers, Version 2.2019. J Natl Compr Canc Netw (2019) 17(4):302-10. doi: 10.6004/jnccn.2019.0019

6. Rizvi S, Gores GJ. Pathogenesis, Diagnosis, and Management of Cholangiocarcinoma. Gastroenterology (2013) 145(6):1215-29. doi: 10.1053/ j.gastro.2013.10.013 
7. Valle JW, Borbath I, Khan SA, Huguet F, Gruenberger T, Arnold D, et al. Biliary Cancer: ESMO Clinical Practice Guidelines for Diagnosis, Treatment and FollowUp. Ann Oncol (2016) 27(suppl 5):v28-37. doi: 10.1093/annonc/mdw324

8. Wang Y, Li J, Xia Y, Gong R, Wang K, Yan Z, et al. Prognostic Nomogram for Intrahepatic Cholangiocarcinoma After Partial Hepatectomy. J Clin Oncol (2013) 31(9):1188-95. doi: 10.1200/JCO.2012.41.5984

9. Valle JW, Furuse J, Jitlal M, Beare S, Mizuno N, Wasan H, et al. Cisplatin and Gemcitabine for Advanced Biliary Tract Cancer: A Meta-Analysis of Two Randomised Trials. Ann Oncol (2014) 25(2):391-8. doi: 10.1093/annonc/mdt540

10. Rizzo A, Ricci AD, Brandi G. Recent Advances of Immunotherapy for Biliary Tract Cancer. Expert Rev Gastroenterol Hepatol (2021) 15(5):527-36. doi: $10.1080 / 17474124.2021 .1853527$

11. Santoni M, Massari F, Di Nunno V, Conti A, Cimadamore A, Scarpelli M, et al. Immunotherapy in Renal Cell Carcinoma: Latest Evidence and Clinical Implications. Drugs Context (2018) 7:212528. doi: 10.7573/dic.212528

12. Mollica V, Rizzo A, Montironi R, Cheng L, Giunchi F, Schiavina R, et al. Current Strategies and Novel Therapeutic Approaches for Metastatic Urothelial Carcinoma. Cancers (Basel) (2020) 12(6):1449. doi: 10.3390/cancers12061449

13. Robert C, Long GV, Brady B, Dutriaux C, Maio M, Mortier L, et al. Nivolumab in Previously Untreated Melanoma Without BRAF Mutation. N Engl J Med (2015) 372(4):320-30. doi: 10.1056/NEJMoa1412082

14. Rosenberg JE, Hoffman-Censits J, Powles T, van der Heijden MS, Balar AV, Necchi A, et al. Atezolizumab in Patients With Locally Advanced and Metastatic Urothelial Carcinoma Who Have Progressed Following Treatment With Platinum-Based Chemotherapy: A Single-Arm, Multicentre, Phase 2 Trial. Lancet (2016) 387(10031):1909-20. doi: 10.1016/S0140-6736(16)00561-4

15. Borghaei H, Paz-Ares L, Horn L, Spigel DR, Steins M, Ready NE, et al. Nivolumab Versus Docetaxel in Advanced Nonsquamous Non-Small-Cell Lung Cancer. N Engl J Med (2015) 373(17):1627-39. doi: 10.1056/NEJMoa1507643

16. Lemery S, Keegan P, Pazdur R. First FDA Approval Agnostic of Cancer Site When a Biomarker Defines the Indication. N Engl J Med (2017) 377 (15):1409-12. doi: 10.1056/NEJMp1709968

17. Mizrahi JD, Shroff RT. New Treatment Options for Advanced Biliary Tract Cancer. Curr Treat Options Oncol (2020) 21(8):63. doi: 10.1007/s11864-020-00767-3

18. Sirica AE, Gores GJ, Groopman JD, Selaru FM, Strazzabosco M, Wei Wang X, et al. Intrahepatic Cholangiocarcinoma: Continuing Challenges and Translational Advances. Hepatology (2019) 69(4):1803-15. doi: 10.1002/hep.30289

19. Abou-Alfa GK, Macarulla T, Javle MM, Kelley RK, Lubner SJ, Adeva J, et al. Ivosidenib in IDH1-Mutant, Chemotherapy-Refractory Cholangiocarcinoma (ClarIDHy): A Multicentre, Randomised, Double-Blind, Placebo-Controlled, Phase 3 Study. Lancet Oncol (2020) 21(6):796-807. doi: 10.1016/S1470-2045(20) 30157-1

20. Abou-Alfa GK, Sahai V, Hollebecque A, Vaccaro G, Melisi D, Al-Rajabi R, et al. Pemigatinib for Previously Treated, Locally Advanced or Metastatic Cholangiocarcinoma: A Multicentre, Open-Label, Phase 2 Study. Lancet Oncol (2020) 21(5):671-84. doi: 10.1016/S1470-2045(20)30109-1

21. Massa A, Varamo C, Vita F, Tavolari S, Peraldo-Neia C, Brandi G, et al. Evolution of the Experimental Models of Cholangiocarcinoma. Cancers (Basel) (2020) 12(8):2308. doi: 10.3390/cancers12082308

22. Rizzo A, Ricci AD, Brandi G. Futibatinib, an Investigational Agent for the Treatment of Intrahepatic Cholangiocarcinoma: Evidence to Date and Future Perspectives. Expert Opin Investig Drugs (2020) 30(4):317-24. doi: $10.1080 / 13543784.2021 .1837774$

23. Sapisochin G, Fernandez de Sevilla E, Echeverri J, Charco R. Liver Transplantation for Cholangiocarcinoma: Current Status and New Insights. World J Hepatol (2015) 7(22):2396-403. doi: 10.4254/wjh.v7.i22.2396

24. Ethun CG, Lopez-Aguiar AG, Anderson DJ, Adams AB, Fields RC, Doyle MB, et al. Transplantation Versus Resection for Hilar Cholangiocarcinoma: An Argument for Shifting Treatment Paradigms for Resectable Disease. Ann Surg (2018) 267(5):797-805. doi: 10.1097/SLA.0000000000002574

25. Park HM, Yun SP, Lee EC, Lee SD, Han SS, Kim SH, et al. Outcomes for Patients With Recurrent Intrahepatic Cholangiocarcinoma After Surgery. Ann Surg Oncol (2016) 23(13):4392-400. doi: 10.1245/s10434016-5454-2

26. Petrowsky H, Fritsch R, Guckenberger M, De Oliveira ML, Dutkowski P, Clavien PA. Modern Therapeutic Approaches for the Treatment of Malignant Liver
Tumours. Nat Rev Gastroenterol Hepatol (2020) 17(12):755-72. doi: 10.1038/ s41575-020-0314-8

27. Llovet JM, Real MI, Montana X, Planas R, Coll S, Aponte J, et al. Arterial Embolisation or Chemoembolisation Versus Symptomatic Treatment in Patients With Unresectable Hepatocellular Carcinoma: A Randomised Controlled Trial. Lancet (2002) 359(9319):1734-9. doi: 10.1016/S0140-6736(02)08649-X

28. Malagari K, Pomoni M, Kelekis A, Pomoni A, Dourakis S, Spyridopoulos T, et al. Prospective Randomized Comparison of Chemoembolization With Doxorubicin-Eluting Beads and Bland Embolization With BeadBlock for Hepatocellular Carcinoma. Cardiovasc Intervent Radiol (2010) 33(3):54151. doi: $10.1007 / \mathrm{s} 00270-009-9750-0$

29. Kulik LM, Carr BI, Mulcahy MF, Lewandowski RJ, Atassi B, Ryu RK, et al. Safety and Efficacy of 90Y Radiotherapy for Hepatocellular Carcinoma With and Without Portal Vein Thrombosis. Hepatology (2008) 47(1):71-81. doi: 10.1002/hep. 21980

30. Salem R, Lewandowski RJ, Kulik L, Wang E, Riaz A, Ryu RK, et al. Radioembolization Results in Longer Time-to-Progression and Reduced Toxicity Compared With Chemoembolization in Patients With Hepatocellular Carcinoma. Gastroenterology (2011) 140(2):497-507.e2. doi: 10.1053/j.gastro.2010.10.049

31. Burger I, Hong K, Schulick R, Georgiades C, Thuluvath P, Choti M, et al. Transcatheter Arterial Chemoembolization in Unresectable Cholangiocarcinoma: Initial Experience in a Single Institution. $J$ Vasc Interv Radiol (2005) 16(3):353-61. doi: 10.1097/01.RVI.0000143768.60751.78

32. Dodson RM, Weiss MJ, Cosgrove D, Herman JM, Kamel I, Anders R, et al. Intrahepatic Cholangiocarcinoma: Management Options and Emerging Therapies. J Am Coll Surg (2013) 217(4):736-50.e4. doi: 10.1016/j.jamcollsurg.2013.05.021

33. Lee JI, Campbell JS. Role of Desmoplasia in Cholangiocarcinoma and Hepatocellular Carcinoma. J Hepatol (2014) 61(2):432-4. doi: 10.1016/j.jhep.2014.04.014

34. Boehm LM, Jayakrishnan TT, Miura JT, Zacharias AJ, Johnston FM, Turaga KK, et al. Comparative Effectiveness of Hepatic Artery Based Therapies for Unresectable Intrahepatic Cholangiocarcinoma. J Surg Oncol (2015) 111 (2):213-20. doi: $10.1002 /$ jso.23781

35. Kim JH, Yoon HK, Sung KB, Ko GY, Gwon DI, Shin JH, et al. Transcatheter Arterial Chemoembolization or Chemoinfusion for Unresectable Intrahepatic Cholangiocarcinoma: Clinical Efficacy and Factors Influencing Outcomes. Cancer (2008) 113(7):1614-22. doi: 10.1002/cncr.23787

36. Gusani NJ, Balaa FK, Steel JL, Geller DA, Marsh JW, Zajko AB, et al. Treatment of Unresectable Cholangiocarcinoma With Gemcitabine-Based Transcatheter Arterial Chemoembolization (TACE): A Single-Institution Experience. J Gastrointest Surg (2008) 12(1):129-37. doi: 10.1007/s11605-007-0312-y

37. Park SY, Kim JH, Yoon HJ, Lee IS, Yoon HK, Kim KP. Transarterial Chemoembolization Versus Supportive Therapy in the Palliative Treatment of Unresectable Intrahepatic Cholangiocarcinoma. Clin Radiol (2011) 66(4):322-8. doi: 10.1016/j.crad.2010.11.002

38. Cercek A, Boerner T, Tan BR, Chou JF, Gonen M, Boucher TM, et al. Assessment of Hepatic Arterial Infusion of Floxuridine in Combination With Systemic Gemcitabine and Oxaliplatin in Patients With Unresectable Intrahepatic Cholangiocarcinoma: A Phase 2 Clinical Trial. JAMA Oncol (2019) 6(1):60-7. doi: 10.1001/jamaoncol.2019.3718

39. Kemeny N, Daly J, Oderman P, Shike M, Chun H, Petroni G, et al. Hepatic Artery Pump Infusion: Toxicity and Results in Patients With Metastatic Colorectal Carcinoma. J Clin Oncol (1984) 2(6):595-600. doi: 10.1200/JCO.1984.2.6.595

40. McMillan DC, McArdle CS. Epidemiology of Colorectal Liver Metastases. Surg Oncol (2007) 16(1):3-5. doi: 10.1016/j.suronc.2007.04.008

41. Ensminger WD, Gyves JW. Clinical Pharmacology of Hepatic Arterial Chemotherapy. Semin Oncol (1983) 10(2):176-82.

42. Cohen AD, Kemeny NE. An Update on Hepatic Arterial Infusion Chemotherapy for Colorectal Cancer. Oncologist (2003) 8(6):553-66. doi: 10.1634/theoncologist.8-6-553

43. Inaba Y, Arai Y, Yamaura H, Sato Y, Najima M, Aramaki T, et al. Phase I/II Study of Hepatic Arterial Infusion Chemotherapy With Gemcitabine in Patients With Unresectable Intrahepatic Cholangiocarcinoma (JIVROSG0301). Am J Clin Oncol (2011) 34(1):58-62. doi: 10.1097/COC. 0b013e3181d2709a

44. Ghiringhelli F, Lorgis V, Vincent J, Ladoire S, Guiu B. Hepatic Arterial Infusion of Gemcitabine Plus Oxaliplatin as Second-Line Treatment for 
Locally Advanced Intrahepatic Cholangiocarcinoma: Preliminary Experience. Chemotherapy (2013) 59(5):354-60. doi: 10.1159/000362223

45. Kasai K, Kooka Y, Suzuki Y, Suzuki A, Oikawa T, Ushio A, et al. Efficacy of Hepatic Arterial Infusion Chemotherapy Using 5-Fluorouracil and Systemic Pegylated Interferon Alpha-2b for Advanced Intrahepatic Cholangiocarcinoma. Ann Surg Oncol (2014) 21(11):3638-45. doi: 10.1245/s10434-014-3766-7

46. Konstantinidis IT, Groot Koerkamp B, Do RK, Gonen M, Fong Y, Allen PJ, et al. Unresectable Intrahepatic Cholangiocarcinoma: Systemic Plus Hepatic Arterial Infusion Chemotherapy Is Associated With Longer Survival in Comparison With Systemic Chemotherapy Alone. Cancer (2016) 122 (5):758-65. doi: 10.1002/cncr.29824

47. Wang X, Hu J, Cao G, Zhu X, Cui Y, Ji X, et al. Phase II Study of Hepatic Arterial Infusion Chemotherapy With Oxaliplatin and 5-Fluorouracil for Advanced Perihilar Cholangiocarcinoma. Radiology (2017) 283(2):580-9. doi: 10.1148/radiol.2016160572

48. Kiefer MV, Albert M, McNally M, Robertson M, Sun W, Fraker D, et al. Chemoembolization of Intrahepatic Cholangiocarcinoma With Cisplatinum, Doxorubicin, Mitomycin C, Ethiodol, and Polyvinyl Alcohol: A 2-Center Study. Cancer (2011) 117(7):1498-505. doi: 10.1002/ cncr. 25625

49. Li J, Wang Q, Lei Z, Wu D, Si A, Wang K, et al. Adjuvant Transarterial Chemoembolization Following Liver Resection for Intrahepatic Cholangiocarcinoma Based on Survival Risk Stratification. Oncologist (2015) 20(6):640-7. doi: 10.1634/theoncologist.2014-0470

50. Wang L, Lin ZG, Ke Q, Lou JY, Zheng SG, Bi XY, et al. Adjuvant Transarterial Chemoembolization Following Radical Resection for Intrahepatic Cholangiocarcinoma: A Multi-Center Retrospective Study. J Cancer (2020) 11(14):4115-22. doi: 10.7150/jca.40358

51. Schernthaner RE, Lin M, Duran R, Chapiro J, Wang Z, Geschwind JF. DelayedPhase Cone-Beam Ct Improves Detectability of Intrahepatic Cholangiocarcinoma During Conventional Transarterial Chemoembolization. Cardiovasc Intervent Radiol (2015) 38(4):929-36. doi: 10.1007/s00270-014-1026-7

52. Zheng WH, Yu T, Luo YH, Wang Y, Liu YF, Hua XD, et al. Clinical Efficacy of Gemcitabine and Cisplatin-Based Transcatheter Arterial Chemoembolization Combined With Radiotherapy in Hilar Cholangiocarcinoma. World J Gastrointest Oncol (2019) 11(6):489-98. doi: 10.4251/wjgo.v11.i6.489

53. Stark S, Wang C, Savic LJ, Letzen B, Schobert I, Miszczuk M, et al. Automated Feature Quantification of Lipiodol as Imaging Biomarker to Predict Therapeutic Efficacy of Conventional Transarterial Chemoembolization of Liver Cancer. Sci Rep (2020) 10(1):18026. doi: 10.1038/s41598-020-75120-7

54. Hong K, Khwaja A, Liapi E, Torbenson MS, Georgiades CS, Geschwind JF. New Intra-Arterial Drug Delivery System for the Treatment of Liver Cancer: Preclinical Assessment in a Rabbit Model of Liver Cancer. Clin Cancer Res (2006) 12(8):2563-7. doi: 10.1158/1078-0432.CCR-05-2225

55. Aliberti C, Carandina R, Sarti D, Pizzirani E, Ramondo G, Mulazzani L, et al. Chemoembolization With Drug-Eluting Microspheres Loaded With Doxorubicin for the Treatment of Cholangiocarcinoma. Anticancer Res (2017) 37(4):1859-63. doi: 10.21873/anticanres.11522

56. Poggi G, Amatu A, Montagna B, Quaretti P, Minoia C, Sottani C, et al. OemTACE: A New Therapeutic Approach in Unresectable Intrahepatic Cholangiocarcinoma. Cardiovasc Intervent Radiol (2009) 32(6):1187-92. doi: 10.1007/s00270-009-9694-4

57. Luo J, Zheng J, Shi C, Fang J, Peng Z, Huang J, et al. Drug-Eluting Beads Transarterial Chemoembolization by CalliSpheres Is Effective and Well Tolerated in Treating Intrahepatic Cholangiocarcinoma Patients: A Preliminary Result From CTILC Study. Med (Baltimore) (2020) 99(12): e19276. doi: 10.1097/MD.0000000000019276

58. Zhou TY, Zhou GH, Zhang YL, Nie CH, Zhu TY, Wang HL, et al. Drug-Eluting Beads Transarterial Chemoembolization With CalliSpheres Microspheres for Treatment of Unresectable Intrahepatic Cholangiocarcinoma. J Cancer (2020) 11(15):4534-41. doi: 10.7150/jca.39410

59. Gates VL, Atassi B, Lewandowski RJ, Ryu RK, Sato KT, Nemcek AA, et al. Radioembolization With Yttrium-90 Microspheres: Review of an Emerging Treatment for Liver Tumors. Future Oncol (2007) 3(1):73-81. doi: 10.2217/ 14796694.3.1.73

60. Mahnken AH. Current Status of Transarterial Radioembolization. World J Radiol (2016) 8(5):449-59. doi: 10.4329/wjr.v8.i5.449
61. Ettorre GM, Levi Sandri GB, Vennarecci G. Yttrium-90 Radioembolization for Hepatocellular Carcinoma Prior to Liver Transplantation: Reply. World J Surg (2017) 41(11):2977. doi: 10.1007/s00268-017-4044-1

62. Ibrahim SM, Mulcahy MF, Lewandowski RJ, Sato KT, Ryu RK, Masterson EJ, et al. Treatment of Unresectable Cholangiocarcinoma Using yttrium-90 Microspheres: Results From a Pilot Study. Cancer (2008) 113(8):2119-28. doi: $10.1002 /$ cncr.23818

63. Hoffmann RT, Paprottka PM, Schon A, Bamberg F, Haug A, Durr EM, et al. Transarterial Hepatic yttrium-90 Radioembolization in Patients With Unresectable Intrahepatic Cholangiocarcinoma: Factors Associated With Prolonged Survival. Cardiovasc Intervent Radiol (2012) 35(1):105-16. doi: 10.1007/s00270-011-0142-x

64. Camacho JC, Kokabi N, Xing M, Prajapati HJ, El-Rayes B, Kim HS. Modified Response Evaluation Criteria in Solid Tumors and European Association for The Study of the Liver Criteria Using Delayed-Phase Imaging at an Early Time Point Predict Survival in Patients With Unresectable Intrahepatic Cholangiocarcinoma Following yttrium-90 Radioembolization. J Vasc Interv Radiol (2014) 25(2):256-65. doi: 10.1016/j.jvir.2013.10.056

65. Bruix J, Sherman M. Practice Guidelines Committee AAftSoLD. Management of Hepatocellular Carcinoma. Hepatology (2005) 42 (5):1208-36. doi: 10.1002/hep.20933

66. Goldberg SN, Grassi CJ, Cardella JF, Charboneau JW, Dodd GD3rd, Dupuy DE, et al. Image-Guided Tumor Ablation: Standardization of Terminology and Reporting Criteria. J Vasc Interv Radiol (2009) 20(7 Suppl):S377-90. doi: 10.1016/j.jvir.2009.04.011

67. Xu HX, Lu MD, Xie XY, Yin XY, Kuang M, Chen JW, et al. Prognostic Factors for Long-Term Outcome After Percutaneous Thermal Ablation for Hepatocellular Carcinoma: A Survival Analysis of 137 Consecutive Patients. Clin Radiol (2005) 60(9):1018-25. doi: 10.1016/j.crad.2005.04.009

68. Xu HX, Xie XY, Lu MD, Chen JW, Yin XY, Xu ZF, et al. Ultrasound-Guided Percutaneous Thermal Ablation of Hepatocellular Carcinoma Using Microwave and Radiofrequency Ablation. Clin Radiol (2004) 59(1):53-61. doi: 10.1016/j.crad.2003.09.006

69. Sutherland LM, Williams JA, Padbury RT, Gotley DC, Stokes B, Maddern GJ. Radiofrequency Ablation of Liver Tumors: A Systematic Review. Arch Surg (2006) 141(2):181-90. doi: 10.1001/archsurg.141.2.181

70. Yousaf A, Kim JU, Eliahoo J, Taylor-Robinson SD, Khan SA. Ablative Therapy for Unresectable Intrahepatic Cholangiocarcinoma: A Systematic Review and Meta-Analysis. J Clin Exp Hepatol (2019) 9(6):740-8. doi: $10.1016 /$ j.jceh.2019.08.001

71. Hong K, Georgiades C. Radiofrequency Ablation: Mechanism of Action and Devices. J Vasc Interv Radiol (2010) 21(8 Suppl):S179-86. doi: 10.1016/ j.jvir.2010.04.008

72. Tuttle R, Nurkin SJ, Hochwald SN. Ablative Therapy for Esophageal Dysplasia and Early Malignancy: Focus on RFA. BioMed Res Int (2014) 2014:642063. doi: $10.1155 / 2014 / 642063$

73. Tanabe KK, Kulu Y. Radiofrequency Ablation for Colon and Rectal Carcinoma Liver Metastases: What's Missing? Gastrointest Cancer Res (2007) 1(4 Suppl 2):S42-6.

74. Han K, Ko HK, Kim KW, Won HJ, Shin YM, Kim PN. Radiofrequency Ablation in the Treatment of Unresectable Intrahepatic Cholangiocarcinoma: Systematic Review and Meta-Analysis. J Vasc Interv Radiol (2015) 26(7):943-8. doi: 10.1016/j.jvir.2015.02.024

75. Carrafiello G, Lagana D, Cotta E, Mangini M, Fontana F, Bandiera F, et al. Radiofrequency Ablation of Intrahepatic Cholangiocarcinoma: Preliminary Experience. Cardiovasc Intervent Radiol (2010) 33(4):835-9. doi: 10.1007/ s00270-010-9849-3

76. Kim JH, Won HJ, Shin YM, Kim KA, Kim PN. Radiofrequency Ablation for the Treatment of Primary Intrahepatic Cholangiocarcinoma. AJR Am J Roentgenol (2011) 196(2):W205-9. doi: 10.2214/AJR.10.4937

77. Giorgio A, Calisti G, DES G, Farella N, DIS A, Amendola F, et al. Radiofrequency Ablation for Intrahepatic Cholangiocarcinoma: Retrospective Analysis of a Single Centre Experience. Anticancer Res (2011) 31(12):4575-80.

78. Brandi G, Rizzo A, Dall'Olio FG, Felicani C, Ercolani G, Cescon M, et al. Percutaneous Radiofrequency Ablation in Intrahepatic Cholangiocarcinoma: A Retrospective Single-Center Experience. Int J Hyperthermia (2020) 37(1):47985. doi: 10.1080/02656736.2020.1763484 
79. Tal AO, Vermehren J, Friedrich-Rust M, Bojunga J, Sarrazin C, Zeuzem S, et al. Intraductal Endoscopic Radiofrequency Ablation for the Treatment of Hilar Non-Resectable Malignant Bile Duct Obstruction. World J Gastrointest Endosc (2014) 6(1):13-9. doi: 10.4253/wjge.v6.i1.13

80. Steel AW, Postgate AJ, Khorsandi S, Nicholls J, Jiao L, Vlavianos P, et al. Endoscopically Applied Radiofrequency Ablation Appears to be Safe in the Treatment of Malignant Biliary Obstruction. Gastrointest Endosc (2011) 73 (1):149-53. doi: 10.1016/j.gie.2010.09.031

81. Figueroa-Barojas P, Bakhru MR, Habib NA, Ellen K, Millman J, JamalKabani A, et al. Safety and Efficacy of Radiofrequency Ablation in the Management of Unresectable Bile Duct and Pancreatic Cancer: A Novel Palliation Technique. J Oncol (2013) 2013:910897. doi: 10.1155/2013/ 910897

82. Wang Y, Cui W, Fan W, Zhang Y, Yao W, Huang K, et al. Percutaneous Intraductal Radiofrequency Ablation in the Management of Unresectable Bismuth Types III and IV Hilar Cholangiocarcinoma. Oncotarget (2016) 7 (33):53911-20. doi: 10.18632/oncotarget.10116

83. Wu TT, Li WM, Li HC, Ao GK, Zheng F, Lin H. Percutaneous Intraductal Radiofrequency Ablation for Extrahepatic Distal Cholangiocarcinoma: A Method for Prolonging Stent Patency and Achieving Better Functional Status and Quality of Life. Cardiovasc Intervent Radiol (2017) 40(2):260-9. doi: 10.1007/s00270-016-1483-2

84. Han Y, Shao N, Xi X, Hao X. Use of Microwave Ablation in the Treatment of Patients With Multiple Primary Malignant Tumors. Thorac Cancer (2017) 8 (4):365-71. doi: 10.1111/1759-7714.12445

85. Medhat E, Abdel Aziz A, Nabeel M, Elbaz T,Zakaria Z, Shousha H, et al. Value of Microwave Ablation in Treatment of Large Lesions of Hepatocellular Carcinoma. J Dig Dis (2015) 16(8):456-63. doi: 10.1111/1751-2980.12259

86. Yu J, Liang P, Yu XL, Cheng ZG, Han ZY, Zhang X, et al. US-Guided Percutaneous Microwave Ablation Versus Open Radical Nephrectomy for Small Renal Cell Carcinoma: Intermediate-Term Results. Radiology (2014) 270(3):880-7. doi: 10.1148/radiol.13130275

87. Yu MA, Liang P, Yu XL, Cheng ZG, Han ZY, Liu FY, et al. SonographyGuided Percutaneous Microwave Ablation of Intrahepatic Primary Cholangiocarcinoma. Eur J Radiol (2011) 80(2):548-52. doi: 10.1016/ j.ejrad.2011.01.014

88. Zhang K, Yu J, Yu X, Han Z, Cheng Z, Liu F, et al. Clinical and Survival Outcomes of Percutaneous Microwave Ablation for Intrahepatic Cholangiocarcinoma. Int J Hyperthermia (2018) 34(3):292-7. doi: 10.1080/ 02656736.2017.1327678

89. Xu C, Li L, Xu W, Du C, Yang L, Tong J, et al. Ultrasound-Guided Percutaneous Microwave Ablation Versus Surgical Resection for Recurrent Intrahepatic Cholangiocarcinoma: Intermediate-Term Results. Int J Hyperthermia (2019) 36(1):351-8. doi: 10.1080/02656736.2019.1571247

90. Davalos RV, Mir IL, Rubinsky B. Tissue Ablation With Irreversible Electroporation. Ann BioMed Eng (2005) 33(2):223-31. doi: 10.1007/s10439005-8981-8

91. Tarek M. Membrane Electroporation: A Molecular Dynamics Simulation. Biophys J (2005) 88(6):4045-53. doi: 10.1529/biophysj.104.050617

92. Delemotte L, Tarek M. Molecular Dynamics Simulations of Lipid Membrane Electroporation. J Membr Biol (2012) 245(9):531-43. doi: 10.1007/s00232-0129434-6

93. Weaver JC, Vaughan TE, Chizmadzhev Y. Theory of Electrical Creation of Aqueous Pathways Across Skin Transport Barriers. Adv Drug Delivery Rev (1999) 35(1):21-39. doi: 10.1016/s0169-409x(98)00061-1

94. Ren F, Li Q, Hu L, Yan X, Gao Z, Zhang J, et al. Safety and Efficacy of Magnetic Anchoring Electrode-Assisted Irreversible Electroporation for Gastric Tissue Ablation. Surg Endosc (2020) 34(2):580-9. doi: 10.1007/ s00464-019-06800-3

95. Narayanan G, Bhatia S, Echenique A, Suthar R, Barbery K, Yrizarry J. Vessel Patency Post Irreversible Electroporation. Cardiovasc Intervent Radiol (2014) 37(6):1523-9. doi: 10.1007/s00270-014-0988-9

96. Cannon R, Ellis S, Hayes D, Narayanan G, Martin RC. 2nd. Safety and Early Efficacy of Irreversible Electroporation for Hepatic Tumors in Proximity to Vital Structures. J Surg Oncol (2013) 107(5):544-9. doi: 10.1002/jso.23280

97. Ueshima E, Schattner M, Mendelsohn R, Gerdes H, Monette S, Takaki H, et al. Transmural Ablation of the Normal Porcine Common Bile Duct With Catheter-Directed Irreversible Electroporation Is Feasible and Does Not
Affect Duct Patency. Gastrointest Endosc (2018) 87(1):300 e1- e6. doi: 10.1016/j.gie.2017.05.004

98. Belfiore MP, Reginelli A, Maggialetti N, Carbone M, Giovine S, Laporta A, et al. Preliminary Results in Unresectable Cholangiocarcinoma Treated by CT Percutaneous Irreversible Electroporation: Feasibility, Safety and Efficacy. Med Oncol (2020) 37(5):45. doi: 10.1007/s12032-020-01360-2

99. Martin EK, Bhutiani N, Egger ME, Philips P, Scoggins CR, McMasters KM, et al. Safety and Efficacy of Irreversible Electroporation in the Treatment of Obstructive Jaundice in Advanced Hilar Cholangiocarcinoma. HPB (Oxford) (2018) 20(11):1092-7. doi: 10.1016/j.hpb.2018.06.1806

100. Hsiao CY, Yang PC, Li X, Huang KW. Clinical Impact of Irreversible Electroporation Ablation for Unresectable Hilar Cholangiocarcinoma. Sci Rep (2020) 10(1):10883. doi: 10.1038/s41598-020-67772-2

101. Coelen RJS, Vogel JA, Vroomen L, Roos E, Busch ORC, van Delden OM, et al. Ablation With Irreversible Electroporation in Patients With Advanced Perihilar Cholangiocarcinoma (ALPACA): A Multicentre Phase I/II Feasibility Study Protocol. BMJ Open (2017) 7(9):e015810. doi: 10.1136/ bmjopen-2016-015810

102. Glazer DI, Tatli S, Shyn PB, Vangel MG, Tuncali K, Silverman SG. Percutaneous Image-Guided Cryoablation of Hepatic Tumors: SingleCenter Experience With Intermediate to Long-Term Outcomes. AJR Am J Roentgenol (2017) 209(6):1381-9. doi: 10.2214/AJR.16.17582

103. Sweeney J, Parikh N, El-Haddad G, Kis B. Ablation of Intrahepatic Cholangiocarcinoma. Semin Intervent Radiol (2019) 36(4):298-302. doi: 10.1055/s-0039-1696649

104. Nag S, DeHaan M, Scruggs G, Mayr N, Martin EW. Long-Term Follow-Up of Patients of Intrahepatic Malignancies Treated With Iodine-125 Brachytherapy. Int J Radiat Oncol Biol Phys (2006) 64(3):736-44. doi: 10.1016/ j.ijrobp.2005.08.029

105. Indar AA, Lobo DN, Gilliam AD, Gregson R, Davidson I, Whittaker S, et al. Percutaneous Biliary Metal Wall Stenting in Malignant Obstructive Jaundice. Eur J Gastroenterol Hepatol (2003) 15(8):915-9. doi: 10.1097/00042737200308000-00013

106. Boulay BR, Birg A. Malignant Biliary Obstruction: From Palliation to Treatment. World J Gastrointest Oncol (2016) 8(6):498-508. doi: 10.4251/wjgo.v8.i6.498

107. Barkun AN, Adam V, Martel M, AlNaamani K. Moses PL. Partially Covered Self-Expandable Metal Stents Versus Polyethylene Stents for Malignant Biliary Obstruction: A Cost-Effectiveness Analysis. Can J Gastroenterol Hepatol (2015) 29(7):377-83. doi: 10.1155/2015/743417

108. Zhu HD, Guo JH, Huang M, Ji JS, Xu H, Lu J, et al. Irradiation Stents vs. Conventional Metal Stents for Unresectable Malignant Biliary Obstruction: A Multicenter Trial. J Hepatol (2018) 68(5):970-7. doi: 10.1016/j.jhep. 2017.12.028

109. Zhu HD, Guo JH, Zhu GY, He SC, Fang W, Deng G, et al. A Novel Biliary Stent Loaded With (125)I Seeds in Patients With Malignant Biliary Obstruction: Preliminary Results Versus a Conventional Biliary Stent. J Hepatol (2012) 56(5):1104-11. doi: 10.1016/j.jhep.2011.12.018

110. Shinohara ET, Guo M, Mitra N, Metz JM. Brachytherapy in the Treatment of Cholangiocarcinoma. Int J Radiat Oncol Biol Phys (2010) 78(3):722-8. doi: 10.1016/j.ijrobp.2009.08.070

111. Wang T, Liu S, Zheng YB, Song XP, Sun BL, Jiang WJ, et al. Clinical Study on Using (125)I Seeds Articles Combined With Biliary Stent Implantation in the Treatment of Malignant Obstructive Jaundice. Anticancer Res (2017) 37 (8):4649-53. doi: 10.21873/anticanres.11867

112. Cui P, Pang Q, Wang Y, Qian Z, Hu X, Wang W, et al. Nutritional Prognostic Scores in Patients With Hilar Cholangiocarcinoma Treated by Percutaneous Transhepatic Biliary Stenting Combined With 125I Seed Intracavitary Irradiation: A Retrospective Observational Study. Med (Baltimore) (2018) 97(22):e11000. doi: 10.1097/MD.0000000000011000

113. Pang Q, Zhou L, Hu XS, Wang Y, Man ZR, Yang S, et al. Biliary Stenting Alone Versus Biliary Stenting Combined With (125)I Particles Intracavitary Irradiation for the Treatment of Advanced Cholangiocarcinoma. Sci Rep (2019) 9(1):11348. doi: 10.1038/s41598-019-47791-4

114. Du E, Wang L, Li CY, Zhang CW, Qu YC, Liu RL, et al. Analysis of Immune Status After Iodine-125 Permanent Brachytherapy in Prostate Cancer. Onco Targets Ther (2017) 10:2561-7. doi: 10.2147/OTT.S137491

115. Kubo M, Satoh T, Ishiyama H, Tabata KI, Tsumura H, Komori S, et al. Enhanced Activated T Cell Subsets in Prostate Cancer Patients Receiving 
Iodine-125 Low-Dose-Rate Prostate Brachytherapy. Oncol Rep (2018) 39 (1):417-24. doi: 10.3892/or.2017.6095

Conflict of Interest: The authors declare that the research was conducted in the absence of any commercial or financial relationships that could be construed as a potential conflict of interest.
Copyright $\odot 2021 \mathrm{Li}$, Chen, Zhu, Yao, Dong and Guo. This is an open-access article distributed under the terms of the Creative Commons Attribution License (CC BY). The use, distribution or reproduction in other forums is permitted, provided the original author(s) and the copyright owner(s) are credited and that the original publication in this journal is cited, in accordance with accepted academic practice. No use, distribution or reproduction is permitted which does not comply with these terms. 